\title{
"O CORPO COMO ARMADURA DE RESISTÊNCIA": CORPOS TRANS* NA CENOGRAFIA DE DIÁRIO EM PROSA E EM POESIA
}

\author{
Rafael Cossetti ${ }^{1}$ \\ Jarbas Vargas Nascimento ${ }^{2}$
}

\begin{abstract}
RESUMO: Este artigo investiga a produção discursivo-literária de sujeitos trans* desenvolvida em uma cenografia de diário em prosa e em poesia. Fundamentamo-nos no aporte teóricometodológico da Análise do Discurso de linha francesa (AD), de modo particular, na perspectiva enunciativo-discursiva proposta por Dominique Maingueneau. Para o autor, a paratopia é o caráter paradoxal dos discursos constituintes, como os discursos filosófico, científico, religioso e literário, os quais se comportam como discursos fundadores que validam a si próprios por meio de suas cenas de enunciação. Nosso objetivo é examinar a constituição da paratopia em um corpus de três discursos literários da coletânea Nós, trans: escrevivências de resistência do Grupo Transcritas Coletivas. Nessa perspectiva, analisamos, a princípio, sua rede interdiscursiva e, a partir dela, concentramo-nos nas três dimensões sobre as quais incide a paratopia: a cenografia, o ethos discursivo e o código linguageiro. Além de constituir-se de forma paratópica nas dimensões analisadas, os resultados da análise indicam que essa produção discursivo-literária de sujeitos trans* busca criar um lugar social para esses sujeitos e seus corpos e fazem-no em resistência à cisgeneridade compulsória.
\end{abstract}

PALAVRAS-CHAVE: Análise do Discurso. Discurso literário. Paratopia. Cenografia. Identidade de gênero.

ABSTRACT: This article investigates the literary-discursive production of trans* subjects developed in a scenography of diary in prose and poetry. We employed the theoreticalmethodological framework of French Discourse Analysis (DA), in particular, in the discursiveenunciative perspective proposed by Dominique Maingueneau. According to the author, paratopia is the paradoxical character of self-constituting discourses, such as philosophical, scientific, religious and literary discourses, which behave like founding discourses that validate themselves through their enunciation scenes. Our aim is to examine the constitution of paratopia in a corpus of three literary discourses from the collection Nós, trans: escrevivências de resistência by Grupo Transcritas Coletivas. In this perspective, we analyzed, at first, its interdiscursive network and, based on it, we concentrated on the three dimensions upon which paratopia falls: the scenography, the discursive ethos and the linguistic code. In addition to being constituted in a paratopic way in the dimensions analyzed, the results of the analysis indicate that this literary-discursive production of trans* subjects seeks to create a social place for these subjects and their bodies and they do so in resistance to compulsory cisgenerity.

\footnotetext{
${ }^{1}$ Doutorando e mestre em Estudos Linguísticos do Programa de Pós-Graduação em Linguística da Universidade Federal do Espírito Santo (UFES), campus Goiabeiras, Vitória, ES, Brasil. Licenciado em Língua Portuguesa e Literaturas de Língua Portuguesa e bacharel em Comunicação Social - Habilitação em Jornalismo também pela UFES. Bolsista CAPES. E-mail: rafaelcossetti@gmail.com

2 Doutor em Letras - Semiótica e Linguística Geral - pela Universidade de São Paulo (USP) e mestre em Língua Portuguesa pela Pontifícia Universidade Católica de São Paulo (PUC-SP). Professor colaborador do Programa de Pós-Graduação em Linguística da Universidade Federal do Espírito Santo (UFES) e professor titular do Programa de Estudos Pós-Graduados em Língua Portuguesa da PUC-SP, São Paulo, SP. E-mail: jvnf1 @ yahoo.com.br
} 
PERcursos Linguísticos • Vitória (ES) •v. 10 •n. 25 • 2020 • ISSN: 2236-2592 • Dossiê:

Discursos de resistência e corpos (re)existentes

KEYWORDS: Discourse Analysis. Literary discourse. Paratopia. Scenography. Gender identity.

\section{Considerações iniciais}

Investigamos, neste artigo, a produção discursivo-literária de sujeitos trans*3 desenvolvida em uma cenografia de diário em prosa e em poesia e a constituição da paratopia nesses discursos. A valorização dessa produção discursiva requer uma luta contra essencialismos e dicotomias. Faz-se necessário, antes de tudo, problematizar posicionamentos assentados em modelos tradicionais e homogêneos, alicerçados em relações políticas de subordinação e de dominação, e refletir sobre mudanças sociais recentes, seja no dia a dia, seja na condução de nossas pesquisas. Abre-se espaço, desta forma, para uma perspectiva que celebra a complexidade da diferença.

Diferentemente do cisgênero, segundo as orientações de Jesus (2012), o transgênero não se identifica, de formas e em graus diferentes, com comportamentos e/ou papéis esperados do gênero que lhe foi designado antes mesmo do momento do seu nascimento. Os termos "transgênero" ou "trans*” funcionam como uma espécie de guarda-chuva utilizado para um conjunto diversificado de sujeitos com vivências bastante distintas, que lutam contra a rede complexa de regulação social que organiza e modela identidades, corpos e comportamentos.

Fundamentamo-nos no aporte teórico-metodológico da Análise do Discurso de linha francesa $(A D)$, de modo particular, na perspectiva enunciativo-discursiva desenvolvida por Maingueneau (1995; 1997; 2008; 2016). A fim de darmos conta do caráter interdisciplinar da análise, dialogamos com a perspectiva teórico-política queer, representada aqui sobretudo pelas obras de Butler $(2002 ; 2015 ; 2016)$. Nesta orientação, aborda-se o gênero social como um conjunto de atos performativos, ou seja, uma norma que se materializa discursivamente. A pesquisa é de cunho analítico e emprega como corpus três discursos literários da coletânea Nós, trans: escrevivências de resistência do Grupo Transcritas Coletivas ${ }^{4}$.

A paratopia, de acordo com Maingueneau (2016), é o caráter paradoxal dos discursos constituintes, como os discursos filosófico, científico, religioso ${ }^{5}$ e literário, os quais se

\footnotetext{
3 Optamos por empregar, ao longo do trabalho, a construção "trans*”, com a presença do asterisco, a fim de evidenciar uma expansão de sentido dos termos "transgênero" e "trans", que passa a se referir não só a mulheres ou homens trans ou transexuais, mas também a várias outras identidades de gênero, como travesti, não binário, gênero-fluido, etc.

${ }^{4}$ Referimo-nos aos discursos por meio da referência "Grupo Transcritas Coletivas", com o intuito de respeitar a forma coletiva de sua produção, indicando nas notas a responsabilidade de cada discurso.

${ }^{5}$ Maingueneau (2016) enquadra o discurso religioso nos discursos constituintes. Nascimento e outros (2009) e Nascimento (2020), entre outras/os pesquisadoras/es, defendem a "constituência” do discurso teológico, na medida
} 
comportam como discursos fundadores que validam a si próprios por meio de suas cenas de enunciação. A paratopia se articula em um investimento de uma cenografia que faz do discurso um lugar de representação de sua própria enunciação, de um ethos discursivo que faz emergir do discurso uma voz que ativa o imaginário estereotípico de um corpo enunciante socialmente avaliado e de um código linguageiro, cuja configuração específica opera sobre a diversidade de zonas e registros de língua com um efeito prescritivo que liga o ato de enunciação que dá origem ao discurso ao universo de sentido que ele realça.

Este estudo busca inserir a Linguística na compreensão do discurso literário e, neste empreendimento, busca valorizar discursos produzidos por sujeitos que historicamente foram e continuam sendo marginalizados, inclusive nos campos científico e acadêmico. O caráter interdisciplinar da $\mathrm{AD}$ viabiliza a pesquisa sobre o resgate e a criação, por meio do discurso literário, de uma memória coletiva na conjuntura atual de produção e de circulação desse tipo de discurso.

Dividimos o texto em quatro seções. Na primeira, discutimos a sedição dos discursos literários produzidos por sujeitos trans* contra uma conjuntura sociocultural de, pelo menos, três séculos que os exclui de diversas maneiras. Abordamos, na segunda, as características do discurso literário, para procedermos à análise na terceira, examinando a constituição da paratopia no nosso corpus. Na seção final, retomamos os resultados da análise e indicamos caminhos possíveis para a continuação e a ampliação deste estudo.

\section{O discurso literário produzido por sujeitos trans* como "contradiscurso"}

Para as diferentes correntes da Teoria Queer, o controle sobre os corpos e identidades de gênero é reconhecido como um dispositivo de poder e saber. Por isso, os sujeitos trans* acabam não sendo vistos como seres humanos, mas como seres abjetos "cujas vidas não são consideradas 'vidas' e cuja materialidade é entendida como 'não importante'” (BUTLER, 2002, p. 161), ou seja, por não serem inteligíveis dentro dos padrões hegemônicos de gênero e de sexualidade baseados em um sistema binário. Para além da aceitação de um lugar "minoritário", a perspectiva teórico-política queer ${ }^{6}$ propõe uma genealogia dos discursos que instituem a heterossexualidade e a cisgeneridade como normas compulsórias.

em que ele serve de base para o discurso religioso, que pode ser compreendido como profundamente institucionalizado, logo, não constituinte.

${ }^{6}$ Concordamos com Pelúcio (2014) no que diz respeito à importância de uma reflexão sobre a forma segundo a qual adaptamos a perspectiva teórico-política queer ao contexto brasileiro. As categorias de gênero, de sexualidade e de raça/etnia se sobrepõem de forma distinta no contexto brasileiro daquele referenciado pelas/os autoras/es estrangeiras/os pertencentes a essa corrente. Essas/es pensadoras/es adotaram a ofensa "queer", uma identidade 
Os discursos literários constituídos em um regime de escrita de si buscam responder a uma conjuntura sociocultural de, pelo menos, três séculos que exclui sujeitos que não se conformam a suas regras compulsórias. A classificação de condutas individuais realizadas no século XIX se assenta na invenção de dois sexos "verdadeiros" no século anterior, de acordo com Laqueur (2001). Essa invenção se dá por intermédio da genitalização da sexualidade e das subjetividades e torna possível a naturalização dos gêneros.

Ao atravessar diversos campos e posicionamentos, o sistema binário masculinofeminino alega que o gênero espelha o sexo e todas as outras características constitutivas dos sujeitos estão atreladas a uma determinação biológica, natural. Em um sistema que só admite duas possibilidades, "a natureza constrói a sexualidade e posiciona os corpos de acordo com as supostas disposições naturais” (BENTO, 2008, p. 17). Tal naturalização de dois sexos pode ser compreendida, se as condições sócio-históricas de surgimento dessa divisão forem recuperadas. Nicholson (2000, p. 18) argumenta que, no século XVIII, transforma-se “[...] o sentido das características físicas, que de sinal ou marca da distinção masculino/feminino passaram a ser sua causa, aquilo que lhe dá origem".

Tanto Nicholson (2000) quanto Bento (2006) ilustram essa mudança no século XVIII com o estudo da literatura médica sobre o corpo desenvolvido por Laqueur (2001). Esse estudo identifica uma mudança importante no século XVIII. Dos gregos ao século XVIII, embora variável, conforme as especificidades de cada conjuntura, circulou uma noção "unissexuada" do corpo. Em contrapartida, uma noção "bissexuada" começa a surgir no século XVIII. Enquanto naquela noção o corpo feminino era concebido como uma versão inferior, incompleta do corpo masculino, nesta os corpos feminino e masculino são "criaturas" diferentes:

[...] a ideia de duas carnes, dois novos sexos distintos e opostos, seria cada vez mais incorporada ao corpo. Os interessados nesses assuntos não mais veriam a mulher como uma versão menor do homem ao longo de um eixo vertical de infinitas gradações, mas como uma criatura completamente diferente ao longo de um eixo horizontal, cujo solo intermediário era vazio (LAQUEUR, 2001, p. 182-183).

A construção de uma divisão natural entre dois sexos conduz o olhar médico na sua tarefa de desfazer "disfarces". O trabalho de assepsia dos gêneros voltado para intersexuais e transexuais e conduzido no espaço hospitalar se intensifica no século XX (BENTO, 2006). Neste sentido, somente uma teoria e uma política pós-identitária conseguem promover uma

apontada mas até então não reivindicada, e conformaram um lugar político. Ademais, como o termo "queer" não significa nada ao senso comum brasileiro, perde-se a politização do termo desqualificador. 
crítica a essa conjuntura, sem que acabem presas por sua lógica de prescrição de identidades e corpos a serem seguidos.

Essas normas prescritivas são rejeitadas, quando se percebe o gênero, como o faz Butler (2002, 2016), como um conjunto de atos performativos ${ }^{7}$, visão que permite compreender as vivências trans* fora dos modelos patológicos. Enquanto performance, o gênero se mostra como um efeito instituído, mantido e repetido no e pelo corpo, não um conjunto de processos socioculturais localizados em corpos sexuados. Segundo Butler (2016), essa performance deve ser entendida como um processo que articula sexo, desejo e prática sexual, como se houvesse uma coerência necessária entre eles.

A contribuição principal desse projeto é viabilizar atos de subversão dos gêneros. Dado que os sujeitos não são como meros resultados de um processo de socialização, podem optar por atualizar ou não as regras compartilhadas. Apropriar-se de termos ofensivos, por exemplo, mostra-se como uma maneira de subversão, uma prática que rivaliza com os valores que tornam esses enunciados depreciativos possíveis. Assim,

[...] palavras, atos, gestos e desejo produzem o efeito de um núcleo ou substância interna, mas o produzem na superfície do corpo, por meio do jogo de ausências significantes, que sugerem, mas nunca revelam, o princípio organizador da identidade como causa. Esses atos, gestos e atuações, entendidos em termos gerais, são performativos, no sentido de que a essência ou identidade que por outro lado pretendem expressar são fabricações manufaturadas e sustentadas por signos corpóreos e outros meios discursivos (BUTLER, 2016, p. 235).

Entretanto, as performances não partem do nada e obedecem às normas vigentes, que são ensinadas aos sujeitos e demandam uma submissão compulsória. Em outras palavras, qualquer performance se mantém vinculada, de uma maneira ou de outra, à matriz heterossexual. Ao mesmo tempo que dita regras a serem seguidas, essa matriz fornece possibilidades de transgressões. Tanto os corpos que se conformam a suas normas quanto os que as subvertem o fazem em referência a ela.

Dentro dessa visão queer, assumimos "contradiscurso" como uma posição de resistência e subversão da matriz cisheterossexual. Os discursos literários que tematizam o próprio sujeito que assume responsabilidade por eles, as escritas de si, reagem a uma cena de interpelação que pergunta “quem é você?”. Um sujeito tematiza a si próprio em um discurso, conforme Butler (2015), quando é obrigado por um sistema de justiça e castigo. No caso dos discursos que

\footnotetext{
${ }^{7}$ Para Butler (2016, p. 56, grifo da autora), "o efeito substantivo [do gênero] é performativamente produzido e imposto pelas práticas reguladoras da coerência do gênero".
} 
PERcursos Linguísticos • Vitória (ES) •v. 10 •n. 25 • 2020 • ISSN: 2236-2592 • Dossiê:

Discursos de resistência e corpos (re)existentes

compõem o corpus, que constituímos, a consideração desses sujeitos como seres abjetos incita que essa cena se configure violentamente. Mesmo assim, os enunciadores respondem e o fazem de modo a possibilitar a discussão e a luta por direitos.

\section{O estatuto do discurso literário na Análise do Discurso}

Como indicamos na seção introdutória, o discurso literário participa, como defende Maingueneau (2016), junto com os discursos filosófico, científico e religioso, de um plano determinado da produção verbal, o dos discursos constituintes. Esses tipos de discursos podem parecer, de antemão, muito distintos para serem agrupados; no entanto, integram uma mesma categoria devido à sua “[...] função (fundar e não ser fundado por outro discurso), [a] certo recorte das situações de comunicação de uma sociedade (há lugares e gêneros vinculados a esses discursos constituintes) e [a] certo número de invariantes enunciativas" (MAINGUENEAU, 2016, p. 61).

Os discursos constituintes se caracterizam pelo acesso ao archeion de uma coletividade, isto é, à sede de autoridade que confere sentido aos atos da coletividade, mantendo um corpo de magistrados e arquivos públicos que estão sempre sendo atualizados. No archeion, associamse "o trabalho de fundação no e pelo discurso, a determinação de um lugar vinculado com um corpo de locutores consagrados e uma elaboração da memória" (MAINGUENEAU, 2016, p. 61). Graças a esse acesso privilegiado, esses discursos se localizam na fronteira entre o mundo comum e um mundo superior, que excede o mundo humano. Essa característica faz com que eles sejam validados por uma cena de enunciação que os autoriza e que servem de origem para os outros tipos de discurso. Esse estatuto único, portanto, torna-os a um só tempo auto e heteroconstituintes: somente um discurso que se constitui gerindo em termos textualdiscursivos sua própria emergência pode servir de fonte para outros discursos.

Maingueneau (2016) aponta que há duas dimensões indissociáveis na emergência desse tipo de discurso. Uma delas se refere a uma ação de se estabelecer legalmente, regrando sua emergência no interdiscurso, enquanto outra se relaciona aos modos de organização, em um sentido de estruturação de elementos que compõem uma totalidade textual. Nos discursos constituintes, a “[...] enunciação se instaura como dispositivo de legitimação de seu próprio espaço, incluindo seu aspecto institucional; ela articula o engendramento de um texto e uma maneira de inscrever-se num universo social" (MAINGUENEAU, 2016, p. 62). Nessa 
perspectiva, uma análise da "constituência"8 desse tipo de discurso deve atentar para a imbricação entre uma atividade enunciativa e uma organização textual.

A inscrição dos discursos constituintes no universo social leva o autor a tratar da produção, do consumo e das relações que esses discursos mantêm com as mais diversas instituições sociais. Sem se filiarem a elas por completo, esses discursos guardam uma condição paradoxal. Assim, o discurso literário, como discurso constituinte, apesar de surgir em diferentes âmbitos sociais, não se fixa em nenhum deles; conserva-se em um pertencimento impossível que alimenta o próprio ato de enunciação que, por sua vez, acaba se revestindo da impossibilidade de inscrição tanto no interior quanto no exterior da sociedade. Quem produz um discurso constituinte "[...] não pode situar-se no exterior nem no interior da sociedade: está fadado a dotar sua obra do caráter radicalmente problemático de seu próprio pertencimento a essa sociedade" (MAINGUENEAU, 2016, p. 68). Resta uma difícil negociação entre lugar e não lugar. Esse caráter paradoxal, que se manifesta discursivamente, é denominado paratopia.

Em seus primeiros trabalhos sobre o discurso literário, Maingueneau (1995) cunha a noção de embreagem paratópica, um conjunto de relações que participam simultaneamente do potencial paratópico dos produtores desses discursos e do mundo delineado por eles. É possível analisá-la em termos de categorias, como a cenografia, o ethos discursivo e o código linguageiro. Tratamos agora de cada uma dessas categorias que são fundamentais para a análise do corpus desenvolvida na próxima seção.

A cenografia é uma das cenas da enunciação ${ }^{9}$, aquela com a qual o interlocutor lida mais diretamente. Mesmo sendo instituída na e pela enunciação logo de início, Maingueneau (2016) lembra que ela legitima o discurso e deve ser por ele legitimada. Em outros termos, a cenografia se confunde com o enunciado que sustenta, e o enunciado, por sua vez, também sustenta a cenografia. No entanto, não se trata de um simples suporte; ela é, antes, um dispositivo capaz de articular a obra e as condições que propiciam sua criação. Maingueneau (1997) esclarece esse dispositivo constituído por elementos da dêixis discursiva ${ }^{10}$, a partir de coordenadas

\footnotetext{
8 O termo "constituência" é específico da $\mathrm{AD}$, especialmente vinculado a diversos textos de Dominique Maingueneau que tratam de discursos constituintes. Serve para enfatizar o caráter de autoinstauração desses discursos.

${ }^{9}$ Em vários trabalhos, Maingueneau (2016) distingue três cenas de enunciação. Além da cenografia, há a cena englobante, que "corresponde ao que se costuma entender por "tipo de discurso"" (MAINGUENEAU, 2016, p. 251), e a cena genérica, negociada por meio de um gênero de discurso específico que participa de uma determinada cena englobante.

${ }^{10}$ A dêixis e a dêixis discursiva possuem a mesma função, mas esta se manifesta "num nível diferente: o do universo de sentido que uma formação discursiva constrói através de sua enunciação. Em geral, as três instâncias da dêixis discursiva não correspondem a um número idêntico de designação nos textos, mas cada uma recobre uma família de expressões em relação de substituição. Distinguir-se-á nesta dêixis o locutor e o destinatário discursivos, a cronografia e a topografia” (MAINGUENEAU, 1997, p. 41, grifos do autor).
} 
PERcursos Linguísticos • Vitória (ES) •v. 10 •n. 25 • 2020 • ISSN: 2236-2592 • Dossiê:

Discursos de resistência e corpos (re)existentes

espaçotemporais implicadas na cena de enunciação, que consistem em um primeiro acesso à cenografia; ela implica uma figura de enunciador e co-enunciador, uma cronografia (um momento) e uma topografia (um lugar), marcas das quais o discurso emerge. Se existe dêixis discursiva é porque a formação discursiva não enuncia a partir de um sujeito, de uma conjuntura histórica e de um espaço evidentemente determináveis, mas a partir da cena que sua enunciação produz. A escolha da cenografia é essencial para constituir e legitimar seu ethos discursivo e para mostrar que o enunciador negociou um código linguageiro adequado àquele universo.

O ethos discursivo é construído por meio do discurso em um processo interativo de influência sobre o co-enunciador. Isto é, concerne um comportamento socialmente avaliado, que é compreendido dentro de uma situação específica de comunicação e de uma conjuntura sócio-histórica determinada. Além disso,

[...] o ethos implica uma maneira de se mover no espaço social, uma disciplina tácita do corpo apreendida através de um comportamento. O destinatário a identifica apoiando-se num conjunto difuso de representações sociais avaliadas positiva ou negativamente, em estereótipos que a enunciação contribui para confrontar ou transformar: o velho sábio, o jovem executivo dinâmico, a mocinha romântica... (MAINGUENEAU, 2008, p. 18).

A ideia de que cada discurso possui um tom específico que aponta para seu enunciador implica também a determinação de uma instância subjetiva encarnada que desempenha a função de fiador. Por meio de indícios textuais, o co-enunciador constrói um conjunto de traços físicos e psíquicos que se sustentam em representações sociais valorizadas ou desvalorizadas, em estereótipos culturais, que são reforçados ou transformados (MAINGUENEAU, 2016). Em concomitância ao desenvolvimento do ethos, a tensão entre enunciação e mundo representado produz o seu oposto, o antiethos (MAINGUENEAU, 1995, 2016), uma estratégia ao mesmo tempo de avaliação negativa da comunidade imaginária concorrente e de enaltecimento do seu próprio ethos discursivo.

O código linguageiro, enfim, diz respeito a uma configuração específica que determinada formação discursiva emprega no momento da enunciação, posto que ela não enuncia por meio de uma língua, mas através de um código específico (MAINGUENEAU, 2016). O uso que se faz da língua é constitutivo de uma formação discursiva e este código participa da autolegitimação do enunciador.

Em se tratando de campo literário, o criador negocia um código linguageiro que lhe é característico, colocando a sua produção em interação com outros códigos e, muitas vezes, com os limites inferior (infralíngua) e superior (supralíngua) de uma língua natural. Nos termos de Maingueneau (2016), enquanto a infralíngua “[...] está voltada para uma origem que seria uma 
PERcursos Linguísticos • Vitória (ES) •v. 10 •n. 25 • 2020 • ISSN: 2236-2592 • Dossiê:

Discursos de resistência e corpos (re)existentes

ambivalente proximidade do corpo, pura emoção" (MAINGUENEAU, 2016, p. 191), a supralíngua “[...] acena com a perfeição luminosa de uma representação idealmente transparente ao pensamento" (MAINGUENEAU, 2016, p. 191).

\section{Corpos trans* na cenografia de diário em prosa e em poesia}

Com base nos apontamentos e nas categorias apresentadas até aqui, analisamos nesta seção os três discursos literários produzidos por sujeitos trans* que compõem o nosso corpus. Os três discursos fazem parte da coletânea Nós, trans: escrevivências de resistência do Grupo Transcritas Coletivas (2017), publicada no formato de livro eletrônico pela LiteraTRANS. Essa editora é voltada exclusivamente à produção discursivo-literária de sujeitos trans* e mantém envolvidos na parte criativa da produção dos livros somente sujeitos trans*. Essa política editorial de valorização garante uma interferência mínima de sujeitos cisgênero e, por consequência, uma produção discursivo-literária lídima desses sujeitos.

Observamos o interdiscurso, a cenografia, o ethos discursivo e o código linguageiro, a fim de examinarmos o funcionamento da paratopia na encenação literária. Uma vez que a paratopia se manifesta em dois níveis, o de discurso constituinte e o de cada produtor/a de um discurso constituinte (MAINGUENEAU, 2016), nossa análise considera a cenografia como produto central do nível do discurso constituinte e o ethos discursivo como projeção da/o produtora/o desses discursos.

Com efeito, predominam, nos discursos selecionados, interdiscursos que tornam possíveis a apresentação de uma conjuntura sócio-histórica de produção de narrativas sobre os sujeitos trans*. Trata-se de uma conjuntura sustentada por um olhar cisheteronormativo sobre esses sujeitos. À primeira vista, temos interdiscursos dos campos médico e político. Mesmo que seja conduzida uma cena na qual se apresente um sujeito enunciador particular, a ideia de uma coletividade trans* percorre esses discursos.

No corpus constituído, verificamos a administração de uma cenografia de diário em prosa, com traços narrativos dominantes, que cedem espaço, em algum ponto, à poesia. Existe uma fluidez no processo de negociação dessa cenografia, na medida em que uma de suas partes se desenvolve em prosa, um regime de enunciação mais objetivo, no qual o enunciador se dirige para o mundo, e outra, em poesia, um regime que direciona o discurso sobre o próprio enunciador, não havendo uma separação explícita entre "eu" e "não eu". Trata-se de uma escolha que agrega à cenografia a valorização da diferença em mais um nível discursivo.

A narração de experiências cotidianas e íntimas funciona, em primeiro lugar, como afirmação de sua presença e de suas angústias enquanto sujeito trans* e, em segundo, uma 
maneira velada de criar a adesão do co-enunciador; talvez contando com a sua disponibilidade devido ao apelo público que as narrativas trans* conservam há tempos (MOIRA, 2018), talvez, o que é mais possível, por optar selecioná-lo, levando em conta um posicionamento que concorde com o seu próprio.

Embora não igualemos a função infralíngua ao regime de enunciação da poesia, para os objetivos deste trabalho, defendemos que há entre eles uma relação especial, dado que, nesse corpus, o retorno enunciativo ao "eu", seja ele individual ou coletivo, é mediado por uma relação de pura emoção, que é comprovada pelo emprego infralinguístico. Diferentemente da prosa, que narra, descreve, explana, nesse recorte, a poesia serve, desse modo, para mostrar a visão específica do "eu" e evocar uma gama indistinta de efeitos que abarcam essa identidade.

Ao longo desses discursos, como veremos, há um movimento, não necessariamente nesta ordem, no qual a predominância da supralíngua, a função coerente e gradual da língua, é substituída pela força da infralíngua, em um grito emotivo de resistência. No momento em que predomina o regime da poesia, o enunciador reflete sobre sua identidade, considerando a diferença que a constitui, e sobre as consequências para a imagem de si, que resultam do tipo de pertencimento dos sujeitos trans* à sociedade. Antes da análise de cada um dos três discursos, apresentamos dados biográficos dos responsáveis pelos discursos. Não os indicamos como uma alternativa à imagem de si mostrada no e pelo discurso, mas como uma extensão dela, aproximando, como é usual em escritas de si, identidade empírica e identidade discursiva.

\section{(1) O corpo como armadura de resistência ${ }^{11}$}

[1] Era mais ou menos 8 da manhã de um dia qualquer, quando fui no mercado do bairro com minha renda no rosto, óculos escuros e peruca chanel vermelha comprar ração para os meus gatos. Notar a expressão indignada das pessoas ao me ver causa em mim um prazer indescritível, é tanto que fico rindo sozinha.

[2] No caminho de volta pra casa, lembrei da minha época de escola, quando passei a transbordar minha transgeneridade e, consequentemente, meu estilo "extravagante" aos olhos da sociedade. A partir daí, as opressões diárias que eu sofria naquele lugar deram espaço a olhares curiosos, espantados e quase sempre silenciosos. Foi aí que percebi que minha expressão funcionava como uma afronta a todos aqueles que me oprimiam e me violentavam; minha aparência se tornou meu escudo, minha armadura, e é assim até hoje.

[3] O armário nunca foi uma opção, então fiz e faço do meu ser a minha maior arma. Mesmo com as consequências, empoderar-me da minha identidade foi um dos maiores atos que pude fazer por mim mesma, contrariando quem achou que iria me reprimir, me acuar, me fazer ter vergonha de mim mesma, pois é isso o que eles querem.

[4] Mas a gente não dá o que eles querem A gente dá o troco

\footnotetext{
${ }^{11}$ Na coletânea, o discurso é assinado por Ana Giselle.
} 
PERcursos Linguísticos • Vitória (ES) •v. 10 •n. 25 • 2020 • ISSN: 2236-2592 • Dossiê:

Discursos de resistência e corpos (re)existentes

\author{
A gente vive \\ A gente resiste \\ Falando, gritando, lutando, tentando ser feliz \\ Até que nos matem \\ (GRUPO TRANSCRITAS COLETIVAS, 2017, p. 19-20).
}

O discurso 1 é de Ana Giselle, recifense de 21 anos, artista e DJ, que se apresenta como “transalien” (GRUPO TRANSCRITAS COLETIVAS, 2017, p. 161). O co-enunciador engajase em uma identidade e um corpo subversivos, que resistem em um lugar (topografia) de espaços rotineiros autorizados à cisgeneridade, como o mercado do bairro e a escola. Essa escolha topográfica é significativa, posto que, nesses ambientes, os sujeitos trans* são confrontados pelo posicionamento regulador da matriz cisheterossexual. À medida que se ostenta um "escudo", uma "armadura", uma "arma", o ethos singular consegue produzir um deslocamento dos estereótipos sobre os sujeitos trans*.

Nesse discurso, a identidade do enunciador é considerada em uma condição sóciohistórica bem delimitada e, ao seu corpo, é reservado um lugar destacado no conjunto de práticas discursivas produtoras de identidades. O processo de constituição e de afirmação da identidade do enunciador passa a admitir o papel medular da diferença e o peso de aspectos corporais e expressivos. Diante disso, concebemos que "a marcação simbólica é o meio pelo qual damos sentido a práticas e a relações sociais, definindo, por exemplo, quem é excluído e quem é incluído" (WOODWARD, 2014, p. 14).

Nesse sentido, o corpo do fiador sobressai como um discurso que se insurge contra a cisgeneridade compulsória dos espaços públicos, intervindo neles. Observamos, em $1 \S 1^{\circ}$ : “notar a expressão indignada das pessoas ao me ver causa em mim um prazer indescritível, é tanto que fico rindo sozinha" (GRUPO TRANSCRITAS COLETIVAS, 2017, p. 19). O enunciador explicita sua posição consciente e percebe seu corpo como um dispositivo discursivo, cujo poder é desestabilizador, como uma "arma" que engendra "[...] uma cadeia de identificações e de negações sucessivas" (PRECIADO, 2014, p. 87) e ameaça uma série de binarismos basilares para o sistema da cisgeneridade compulsória.

Em sua posição de enfrentamento da cisgeneridade, o enunciador se afirma como trans* não passável, quer dizer, define-se como uma identidade que não se conforma aos aspectos culturais, que caracterizam as identidades cisgênero e não sente "vergonha" por isso: "o armário nunca foi uma opção, então fiz e faço do meu ser a minha maior arma" (GRUPO TRANSCRITAS COLETIVAS, 2017, p. 19). O conceito de passabilidade é visto pela primeira no âmbito do gênero social com o estudo de Garfinkel (2006 [1967]), apesar de o autor não 
empregar, de maneira explícita, essa terminologia. A passabilidade, como indicam Butler (2016) e Bento (2008), pode ser compreendida como a construção de uma expressão de gênero inteligível, que se adequa à cisgeneridade compulsória.

Se considerarmos o embreante código linguageiro, a narração dominante, nessa cenografia, demanda a utilização de um de seus princípios mais básicos, o tempo pretérito perfeito. Nesse exemplar, a narração que rememora experiências passadas do enunciador decompõe o tempo em dois momentos diferentes, um mais remoto, da "época de escola", da fragilidade, e outro mais recente, de resistência, de ocupação dos espaços públicos. A dinâmica entre um momento mais remoto e um mais recente reforça outra instância que ratifica essa cenografia: um tempo (cronografia) de mudança.

Por sua opção narrativa, a escrita de si depende da presença constante da primeira pessoa do singular. Dentro do movimento de deslocamento do regime enunciativo da prosa para o da poesia, em $1 \S 4^{\circ}$, o "eu" cede seu lugar para "a gente". A identidade do enunciador, agora em uma perspectiva mais coletiva, afirma a luta e a resistência dos sujeitos trans* e protesta, no último enunciado, contra a violência da cisgeneridade compulsória.

O segmento desse discurso que usa o regime da poesia manifesta uma identidade alargada. O "eu" que retorna sobre si mesmo, que caracteriza a poesia, faz-se aqui "eu" coletivo. Junto com os outros embreantes, essa identidade estabelece representações da paratopia de gênero, que são gerenciadas com base na marcação simbólica que recebem socialmente certas identidades de gênero, certas expressões de gênero e certos corpos.

\section{(2) 22 de agosto $^{12}$}

[1] Um corpo em disforia. Dor Um corpo trans. Um soco, dor Raiva, sangue... dor Gozo, bocejo. Ódio, ócio Dor Odiar-se, reparar-se, remendar-se Transmutar-se, transformar-se

[2] Hoje eu me olhei no espelho, nu. E detestei. Eu cuspi no reflexo, ameacei cravar uma faca no meu peito e nunca mais respirar. Segurei minhas coxas com raiva, enfiei minhas unhas nelas num movimento animalesco e gritei. Fiz o mesmo com a cintura, belisquei minhas cicatrizes (como se pudesse me livrar delas). Bem, eu não consegui. E eu me odeio. Eu me odeio por não conseguir e me odeio ainda mais por persistir.

[3] Vocês nunca vão saber como é não se sentir bom o bastante para nada.

\footnotetext{
${ }^{12} \mathrm{O}$ discurso é assinado por Kaique Theodoro.
} 
[4] Eu escrevo por sobrevivência. Parece que as palavras saem da minha boca com o peso de toda essa existência, pouco a pouco. Parece que consigo me livrar de mim assim. Eu só queria dizer que estou aqui.

[5] E dói.

(GRUPO TRANSCRITAS COLETIVAS, 2017, p. 40).

Kaique Theodoro, homens trans de 22 anos, carioca, modelo, músico autodidata e ator do grupo Transarte, assina o discurso 2, cuja cenografia inverte o movimento prosa-poesia sistematizado no discurso anterior. Aqui, a poesia do recorte inicial vai se deslocando para a prosa. Nesse discurso, a imagem de si e a de seu corpo são confrontadas na fala do enunciador.

Em primeiro lugar, o enunciador se move por um lugar (topografia) de intimidade doméstica, para em frente ao espelho e observa seu corpo: há uma divergência entre sua identidade de gênero e sua materialidade corporal. Esse ethos discursivo do isolamento, em uma dimensão experiencial, é sancionado pela falta de um diálogo explícito com outras corporalidades. Essa cena de fechamento em si, porém, cria um efeito intimista, cujo objetivo é ganhar a adesão do co-enunciador. A busca pela adesão do co-enunciador pode ser comprovada, em uma visada patemizante reforçada (CHARAUDEAU, 2007) ${ }^{13}$, no recorte "vocês nunca vão saber como é não se sentir bom o bastante para nada" (GRUPO TRANSCRITAS COLETIVAS, 2017, p. 40).

Menciona-se, em segundo lugar, a "disforia" de gênero, desde o princípio, e seus efeitos sobre o enunciador são desenvolvidos ao longo da cenografia de diário. É importante lembrar que, apesar de nem todo trans* ser disfórico, essa condição de ansiedade duradoura, que se origina do descompasso entre identidade e expressão corporal, pode marcar a experiência de alguns sujeitos trans*. A enunciação fica, assim, respaldada por uma cronografia de lamento, de dor, que remete à instância temporal da reivindicação coletiva de acesso ao processo transexualizador e à cidadania plena.

A paratopia de gênero, como está expressa em "hoje eu me olhei no espelho, nu. E detestei” (GRUPO TRANSCRITAS COLETIVAS, 2017, p. 40) estabelece, na figura do espelho, um embreante que dialoga com o mito do duplo ${ }^{14}$. Por intermédio desse objeto, o enunciador lida com uma percepção de sua materialidade física que não condiz com a imagem que tem de si. As escolhas discursivas nos diferentes níveis desse discurso criam um efeito de

\footnotetext{
${ }^{13}$ Extrapola nosso objetivo discutir o conceito de visada patemizante de Charaudeau (2007). Em suma, quando o sujeito enunciador reforça a visada patemizante de seu discurso, quer dizer que intenciona emocionar seu público, para conseguir sua adesão.

14 As relações entre o mito do duplo e a produção do Grupo Transcritas Coletivas são discutidas em Cossetti (2019).
} 
expressividade que evocam uma corporalidade aflita. Esse fiador revela a necessidade de adequar seu corpo, de "transmutar-se, transformar-se" (GRUPO TRANSCRITAS COLETIVAS, 2017, p. 40), o que aponta para uma superação do duplo da estética romântica, segundo o qual se costumava aludir à inversão, no íntimo das personagens, de princípios morais.

A paratopia, nesse discurso, também está na posição do enunciador como pertencente à classe artística, literária. Devido ao seu lugar social incongruente, a/o artista precisa discursivizar, em suas obras, sua errância, fazendo emergir nelas variadas representações da paratopia.

\begin{abstract}
A paratopia do escritor, na qualidade de condição da enunciação, também é seu produto; é por meio da paratopia que a obra pode vir à existência, mas é também essa paratopia que a obra deve construir em seu próprio desenvolvimento. Na qualidade de enunciação profundamente ameaçada, a literatura não pode dissociar seus conteúdos da legitimação do gesto que os propõe; a obra só pode configurar um mundo se este for dilacerado pela remissão ao espaço que torna possível sua própria enunciação (MAINGUENEAU, 2016, p. 119).
\end{abstract}

$\operatorname{Em} 2 \S 4^{\circ}$, a paratopia atravessa a figura da/o artista que se expressa pela palavra escrita: "eu escrevo por sobrevivência" (GRUPO TRANSCRITAS COLETIVAS, 2017, p. 40). O potencial paratópico de uma vivência ameaçada se transforma em ato ameaçado, o da literatura. A pressuposta reincidência desse ato, já que dele depende a sobrevivência do enunciador, é afiançada pelo título "22 de agosto", que, ao que tudo indica, trata-se de um dia como qualquer outro.

Ademais, em relação ao código linguageiro, notamos que o percurso da função infralíngua, no recorte dominado pela poesia, para a supralíngua, configura uma tentativa de o enunciador racionalizar e controlar sua dor. Essa atitude resulta em uma repetição do "eu”, em um movimento cenográfico de afirmação de sua identidade e, por conseguinte, de consciência da interferência discursiva do discurso constituinte no espaço social.

Em $2 \S 5^{\circ}$, reitera-se a função supralinguística e conclui-se o discurso, reafirmando a dor do enunciador, agora de forma sucinta e estoica, se a compararmos com o primeiro recorte dessa configuração cenográfica, no qual prevalece a função infralíngua.

\title{
(3) Florescer no feminino ${ }^{15}$ \\ [1] É difícil se amar. É difícil se querer bem.
}

\footnotetext{
${ }^{15} \mathrm{O}$ discurso é assinado por Lana de Holanda.
} 
[2] Coluna reta! Boca fechada! Pernas cruzadas! Senta igual homem! Essa maquiagem tá muito forte! Quer ser mulher? Mulheres não falam isso. Mulheres não escrevem isso. Mulheres não postam isso. E o silicone, tá juntando dinheiro? Mas não pode ser muito grande, vai parecer uma puta. E a buceta? Ah não! Mulher de pau não pode! Mulher tem que ter buceta, mulher é buceta! E os namorados? Mas como vocês se relacionam? Ah tá, ele é gay. Ué, mas você não é gay? Trans não é gay? Vamos falar a verdade, é tudo igual né. Pouca vergonha. Falta de respeito. Isso é falta de Deus. Falta de amor próprio. Doença. Eu não entendo direito como funciona esse negócio de nascer de um sexo, mas se perceber de outro. Me explica? Ah não, explica não. Agora tô sem tempo. Eu não entendo, mas respeito, isso que importa. Drama! E daí que o Brasil é o país que mais mata pessoas trans? Morre gente todo dia. Todo tipo de gente. É muita vitimização. E quem garante que essas travestis não estavam fazendo algo errado? Prostituição? Quem quer trabalha. Você mesma trabalha, por que as outras não fazem igual? Transfobia?! Ah não, é muita palavra nova. Muito esquerdismo. Mimimi.

[3] É preciso tentar. É preciso seguir.

[4] Não me curvo, além do que já sou curvada normalmente. Não desvio meu olhar. Não boto galho dentro. Ok, às vezes olho pro chão. Mas esse é um hábito que tenho desde pequena. Andar olhando pro chão. O que será que estava procurando? Eu tava me procurando pelo caminho? Me encontrei, mas a mania ficou. "O chão é duro demais", minha terapeuta disse. Aí, quando lembro dela falando isso, eu levanto o olhar. Vejo alguns rostos, alguns olhares, vejo o sol, as flores, os carros e as paredes. Quando me dou conta, já estou olhando pro chão de novo. Não sofro por isso, nem fico remoendo. Só me preocupo com a postura mesmo. Com os eventuais problemas de coluna.

[5] Mas, nessa vida escrota, eu aprendi muita coisa. Aprendi a dizer "ela" quando dizem "ele". Aprendi a falar "Lana" quando dizem o outro nome. Aprendi a apenas revirar os olhos e respirar fundo com quem não vale a pena bater de frente. Aprendi a ser política. Aprendi a sorrir e ver beleza no meio de tanta exigência e de tanta imposição. Aprendi a ver isso, porque realmente existe muita beleza e muitos motivos pra sorrir. Nem tudo são flores, mas nem tudo são dores. Não, não. "Você é forte", eles dizem. Eu me pergunto se realmente sou, ou se é só a máscara que decidi usar. Sou sim, sou forte. Não alguém do planeta Krypton, mas forte. Apenas o suficiente. Forças e fraquezas, sorrisos e choros, sinceridade e deboche, curiosidade e preguiça. Muita preguiça. Paixões, amor pelo Amor, tesão e sono. Gargalhadas incontroláveis. Essas coisas fazem eu ser a mulher que sou. A mulher que muitos duvidam. A mulher que eu vivo. A mulher que resiste. A mulher que brota e floresce diariamente. A mulher de pau. A mulher humana. A mulher eu. Lana.

(GRUPO TRANSCRITAS COLETIVAS, 2017, p. 112-113).

O discurso 3 é de autoria de Lana de Holanda, mulher trans de 26 anos. Nascida em São Gonçalo, região metropolitana do Rio de Janeiro, é estudante de Serviço Social na Universidade Federal do Rio de Janeiro (UFRJ), criou a página Transgressiva e foi assessora parlamentar da vereadora Marielle Franco (PSOL-RJ). Nesse discurso, o enunciador particulariza a voz do Outro, de posicionamento inconciliável, mostrando um antiethos bem delimitado que orienta sua paratopia criadora.

Por todo o parágrafo $3 \S 2^{\circ}$, introduzem-se vozes resultantes de um posicionamento heteroconformista opressor que ordena o cumprimento de normas de gênero, baseadas em marcas biológicas, como a genitália. A construção dessas vozes retoma um contexto sócio- 
PERcursos Linguísticos • Vitória (ES) •v. 10 •n. 25 • 2020 • ISSN: 2236-2592 • Dossiê:

Discursos de resistência e corpos (re)existentes

histórico de controle sobre os corpos e de patologização de identidades dissidentes, o qual foi examinado de forma sucinta em uma parte anterior de nossa pesquisa.

O caráter e, consequentemente, o corpo do Outro se mostram como uma personagem múltipla que enlaça o potencial paratópico dos sujeitos trans* ao seu discurso. O ethos discursivo associado ao posicionamento queer do enunciador é de autopertencimento, de uma corporalidade, que se revela em uma topografia de resistência rotineira e pública. $\mathrm{O}$ enfrentamento entre esses dois modos de existir fazem funcionar a paratopia de gênero, que é condição e produto dessa enunciação.

Essa instabilidade entre autopertencimento e opressão, no nível do embreante código linguageiro, é abordada na seleção de itens lexicais e expressões que ajudam a construir um caráter controlador e transfóbico para o antiethos. Aparecem, ao longo de $3 \S 2^{\circ}$, por exemplo, "doença", "vitimização", "pouca vergonha", "muito esquerdismo" para indicar a condição social dos sujeitos trans*. Nesse mesmo parágrafo, há uma série de enunciados diretivos, “Coluna reta! Boca fechada! Pernas cruzadas! Senta igual homem!” (GRUPO TRANSCRITAS COLETIVAS, 2017, p. 112).

Em resposta, o enunciador dirige-se, em $3 \S 3^{\circ}$, a si e ao seu grupo com as seguintes diretivas: “É preciso tentar. É preciso seguir” (GRUPOS TRANSCRITAS COLETIVAS, 2017, p. 112). O efeito intimista criado, nesse exemplar, pela cenografia de diário não deixa de ser uma forma de maquiar a persuasão pretendida. De acordo com Amossy (2007), todo ato enunciativo, mesmo quando não se mostra argumentativo em um senso mais específico do termo, acaba orientando a forma de ver e refletir do co-enunciador. Podemos defender que essa dinâmica é destinada a co-enunciadores que compartilham um posicionamento aproximado ao do enunciador.

O enunciador aborda sua corporalidade como um dispositivo discursivo que se insurge contra a cisgeneridade compulsória, ocupando os espaços públicos, como acontece no discurso 1. A consciência do poder de seu próprio corpo é conquistada por meio de uma cronografia de aprendizagem gradual, descrito no começo de $3 \S 5^{\circ}$, que é, igualmente, tempo de mudança, de reivindicação. Então, à interpelação controladora do Outro - "E a buceta? Ah não! Mulher de pau não pode! Mulher tem que ter buceta, mulher é buceta!” (GRUPO TRANSCRITAS COLETIVAS, 2017, p. 112) -, que equivale genitália à identidade de gênero, o corpo da "mulher de pau" responde com a asserção de sua presença desestabilizadora.

O título "Florescer no feminino" se insere nesse tempo de aprendizagem gradual e descreve um processo reiterado "diariamente". Essa cena de metamorfose reproduz o mito literário do duplo, presença constante em toda a coletânea, que se comporta aqui como um 
modo de gerenciamento discursivo que emerge da dificuldade do processo encarado pelo enunciador de substituição irreversível de uma identidade ilusória por uma identidade legítima.

A poesia, em $3 \S 5^{\circ}$, é elaborada pelo retorno do enunciador a si mesmo em um movimento circular, que vai certificando, em uma enumeração, diversas características dessa identidade discursiva legítima. Nesse recorte, o ritmo deve ser marcado pela repetição do item "mulher", que funciona, nesse retorno sobre si, como uma afirmação da identidade de gênero.

Termina-se o discurso em: "A mulher humana. A mulher eu. Lana." (GRUPO TRANSCRITAS COLETIVAS, 2017, p. 113). O extravasamento do "eu" que se sobressai no segmento em poesia é, em última instância, encerrado com a afirmação do nome, cujo peso simbólico também pode ser constatado em outras escritas de si de sujeitos trans*.

Nos discursos analisados, cumulam-se vários efeitos da paratopia de identidade. A paratopia de gênero se encontra em primeiro plano e combina-se com a paratopia do tipo social e a do tipo corporal. A essa combinação de efeitos, soma-se o gerenciamento de dois regimes de enunciação diferentes, a prosa e a poesia, resultando em uma atualização da paratopia nessas condições sócio-históricas de produção discursivo-literária.

\section{Considerações finais}

Examinamos, neste trabalho, o ato de criação discursivo-literário de sujeitos trans* desenvolvido em uma cenografia de diário em prosa e em poesia, buscando focalizar sobretudo a dimensão corporal encenada. Os resultados da análise confirmam que, além de constituir-se de forma paratópica nas três dimensões analisadas, essa produção discursivo-literária busca criar um lugar social para esses sujeitos e seus corpos por meio da resistência à matriz cisheterossexual.

Por estarem alicerçados em um posicionamento queer, segundo o qual o gênero é performado discursivamente e, por isso, pode apresentar-se em inúmeras expressões, esses discursos geram em suas cenas um dissenso com um posicionamento conversador e biologizante do gênero. O conflito entre esses dois posicionamentos insere, pois, nesses discursos uma caracterização pejorativa para os associados a um posicionamento cisheteroconformista e uma apreciativa para os vinculados ao posicionamento queer, no qual se localizam todos os enunciadores dos discursos analisados.

Defendemos, ainda, que há nesse corpus um agenciamento coletivo da enunciação (DELEUZE; GUATTARI, 2017), no e por meio do qual cada característica individual citada é 
PERcursos Linguísticos • Vitória (ES) •v. 10 •n. 25 • 2020 • ISSN: 2236-2592 • Dossiê:

Discursos de resistência e corpos (re)existentes

índice para uma história maior, coletiva ${ }^{16}$. Nesses discursos, um enunciador, que representa um grupo, coloca-se em uma posição de confronto em relação ao pertencimento social reservado às identidades e aos corpos do seu grupo.

Os discursos aqui analisados abarcam uma luta travada pela liberdade de expressão da identidade de gênero e equivalem a uma porção pequena de um tipo de produção discursiva bastante heterogênea, que requer outras investigações linguístico-discursivas. Julgamos, por fim, que a análise de escritas de si torna possível uma expansão do estudo sobre a representação da paratopia de identidade. Esse movimento ajudaria a explicitar o discurso literário em uma dimensão também pedagógica, configurando-se como uma prática discursiva que indaga os comportamentos e/ou papéis de gênero estabilizados para determinada identidade. Além disso, este tipo de discurso auxilia na chancela ou na desestabilização do imaginário de gênero corrente, ou seja, as identidades discursivas podem ser agenciadas como embreantes paratópicos resistentes à estratificação das identidades de gênero, baseada em argumentos que a fazem parecer natural, imutável.

\section{Referências}

AMOSSY, R. O lugar da argumentação na Análise do Discurso: abordagens e desafios contemporâneos. Trad. Adriana Zavaglia. Filologia e Língua Portuguesa, São Paulo, n. 9, p. 121-146, 2007.

BENTO, B. A reinvenção do corpo: sexualidade e gênero na experiência transexual. Rio de Janeiro: Garamond, 2006.

BENTO, B. O que é transexualidade. São Paulo: Brasiliense, 2008.

BUTLER, J. Como os corpos se tornam matéria: entrevista com Judith Butler. Trad. Susana Bornéo Funck. Estudos feministas, Florianópolis, v. 10, n. 1, p. 155-167, 2002. Entrevista concedida a Baukje Prins e Irene Costera Meijer. Disponível em: http://www.scielo.br/pdf/ref/v10n1/11634.pdf. Acesso em: 5 maio 2020.

BUTLER, J. Relatar a si mesmo: crítica da violência ética. Trad. Rogério Bettoni. Belo Horizonte: Autêntica, 2015.

BUTLER, J. Problemas de gênero: feminismo e subversão da identidade. Trad. Renato Aguiar. 11. ed. Rio de Janeiro: Civilização Brasileira, 2016.

\footnotetext{
${ }^{16}$ Em Cossetti (2019), esse movimento discursivo, em que histórias e características individuais servem de índice para uma história coletiva, é analisado em outras cenografias.
} 
PERcursos Linguísticos • Vitória (ES) •v. 10 •n. 25 • 2020 • ISSN: 2236-2592 • Dossiê:

Discursos de resistência e corpos (re)existentes

CHARAUDEAU, P. A patemização na televisão como estratégia de autenticidade. Trad. Renato de Mello. 2007. Disponível em: http://www.patrick-charaudeau.com/A-patemizacaona-televisao-como.html. Acesso em: 6 maio 2020.

COSSETTI, R. Diferença e coletividade: a produção discursivo-literária de sujeitos transgêneros. Orientador: Jarbas Vargas Nascimento. 2019. 145 f. Dissertação (Mestrado em Estudos Linguísticos) - Programa de Pós-Graduação em Linguística, Universidade Federal do Espírito Santo, Vitória, 2019.

DELEUZE, G.; GUATTARI, F. Kafka: por uma literatura menor. Trad. Cíntia Vieira da Silva. 1. ed. 3. reimp. Belo Horizonte: Autêntica, 2017.

GRUPO TRANSCRITAS COLETIVAS. Nós, trans: escrevivências de resistência. São Paulo: LiteraTRANS, 2017. E-book.

GARFINKEL, H. Passing and the managed achievement of sex status in an "intersexed" person. In: STRYKER, Susan; WHITTLE, Stephen (ed.). The transgender studies reader. New York: Routledge, 2006. p. 58-93.

JESUS, J. G. Orientações sobre identidade de gênero: conceitos e termos. Guia técnico sobre pessoas transexuais, travestis e demais transgêneros, para formadores de opinião. 2. ed. rev. ampl. Brasília: Ser-Tão/UFG, 2012. Disponível em: http://www.diversidadesexual.com.br/wpcontent/uploads/2013/04/G\%C3\%8ANERO-CONCEITOS-E-TERMOS.pdf. Acesso em: 18 fev. 2020.

LAQUEUR, T. Inventando o sexo: corpo e gênero dos gregos a Freud. Trad. Vera Whately. Rio de Janeiro: Relume Dumará, 2001.

MAINGUENEAU, D. O contexto da obra literária: enunciação, escritor, sociedade. Trad. Marina Appenzeller. São Paulo: Martins Fontes, 1995.

MAINGUENEAU, D. Novas tendências em análise do discurso. Trad. Freda Indursky. 3. ed. Campinas: Pontes, 1997.

MAINGUENEAU, D. Gênese dos discursos. Trad. Sírio Possenti. São Paulo: Parábola, 2008.

MAINGUENEAU, D. Discurso literário. Trad. Adail Sobral. 2. ed. São Paulo: Contexto, 2016.

MOIRA, A. De quando elas e eles contam suas histórias: uma breve genealogia das autobiografias trans mostra a potência dessas obras. Suplemento Pernambuco, Recife, n. 145, p. 4-5, mar. 2018. Disponível em: http://www.suplementopernambuco.com.br/images/pdf/PE_145_web.pdf. Acesso em: 23 abr. 2020.

NASCIMENTO, J. V. O discurso teológico como discurso constituinte. In: NASCIMENTO, J. V.; FERREIRA, A. (org.). Discursos constituintes. São Paulo: Blucher, 2020. p. 34-59.

NASCIMENTO, J. V. et al. A parábola do filho pródigo. São Paulo: LPB, 2009. 
PERcursos Linguísticos • Vitória (ES) •v. 10 •n. 25 • 2020 • ISSN: 2236-2592 • Dossiê:

Discursos de resistência e corpos (re)existentes

NICHOLSON, L. Interpretando o gênero. Trad. Luiz Felipe Guimarães Soares. Estudos Feministas, Florianópolis, v. 8, n. 2, p. 9-41, 2000.

PELÚCIO, L. Traduções e torções ou o que se quer dizer quando dizemos queer no Brasil? Periódicus, Salvador, v. 1, n. 1, p. 68-91, maio/out. 2014. Disponível em: https://portalseer.ufba.br/index.php/revistaperiodicus/article/view/10150/7254. Acesso em: 2 abr. 2020.

PRECIADO, [Paul B.]. Manifesto contrassexual: práticas subversivas de identidade sexual. Trad. Maria Paula Gurgel Ribeiro. São Paulo: n-1, 2014.

WOODWARD, K. Identidade e diferença: uma introdução teórica e conceitual. Trad. Tomaz Tadeu da Silva. In: SILVA, T. T. (org.). Identidade e diferença: a perspectiva dos estudos culturais. 15. ed. Petrópolis, RJ: Vozes, 2014. p. 7-72. 